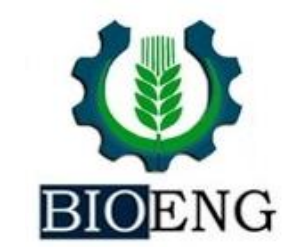

\section{MEDIDAS PARA MINIMIZAR A EMISSÃO DE AMÔNIA NA PRODUÇÃO DE FRANGOS DE CORTE: REVISÃO}

F. C. Sousa ${ }^{1 *}$, I. F. F. Tinôco ${ }^{1}$, M. O. Paula ${ }^{1}$, A. L. Silva ${ }^{1}$, C. F. Souza ${ }^{1}$, F. J. F. Batista ${ }^{2}$, M. Barbari ${ }^{3}$

${ }^{1}$ UFV - Univ Federal de Viçosa, Viçosa, MG, Brasil

${ }^{2}$ Universidade de Évora, Évora, Portugal

${ }^{3}$ Università degli Studi di Firenze, Florença, Itália

Article history: Received 24 October 2015; Received in revised form 29 February 2016; Accepted 02 March 2016; Available online 21 March 2016.

\title{
RESUMO
}

As principais fontes de geração de amônia estão nas atividades agrícolas, com grande representação da avicultura, por utilizar sistemas de confinamento com adoção de cama sobreposta ao piso para reter os dejetos. A amônia produzida nos sistemas de produção de frangos de corte gera diversos danos aos animais, humanos e ao meio ambiente. A principal fonte de amônia nos dejetos depositados na cama é o nitrogênio excretado. Com a adoção de técnicas apropriadas de manejo do ambiente, por meio da adequada ventilação e manejo da cama, pelo controle de $\mathrm{pH}$, temperatura e umidade são possíveis reduções significativas na emissão de amônia, bem como com a utilização de aditivos e controle do adequado teor de nitrogênio que é fornecido nas rações.

Palavras-chave: avicultura, poluição atmosférica, qualidade do ar

\section{ACTIONS TO MINIMIZE AMMONIA EMISSION IN BROILER PRODUCTION: REVIEW}

\begin{abstract}
The main sources of ammonia generation are in agricultural activities, with great representation of poultry, by using feed lot systems with adoption of deep bedding on floor to retain the manure. Ammonia produced in broiler systems production generates damages to animals, humans and environment. The main source of ammonia in the manure deposited on the bed is the excreted nitrogen. With the adoption of appropriate techniques of environmental management, through of adequate ventilation and bed management, control of $\mathrm{pH}$, temperature and humidity are possible significant reductions in ammonia emission, as well as with the use of additives and control the appropriate nitrogen content that is provided in the rations.
\end{abstract}

Keywords: air pollution, air quality, poultry

*fernanda.sousa@ufv.br 


\section{INTRODUÇÃO}

As atividades agrícolas são as principais fontes de geração de emissão de amônia $\left(\mathrm{NH}_{3}\right)$ para atmosfera, ocorrendo principalmente nas instalações pecuárias, ou confinamentos, onde existe acúmulo de dejetos (Atia, 2008). Nos Estados Unidos e Canadá a agricultura é responsável por três quartos das emissões de amônia, sendo que desse total a maior parte é dada a produção animal (Bittman \& Mikkelsen, 2009).

A avicultura de corte tem se destacado entre os principais sistemas de confinamento, por ser a forma mais barata e eficiente de produção de proteína de origem animal para alimentar a crescente população mundial, além de apresentar diversas vantagens em relação a outros sistemas, como por exemplo, curtos ciclos de produção, elevado nível tecnológico, requer pequeno espaço para produção e utiliza menos água e energia (Mendes et al., 2012).

O desempenho do frango de corte é diretamente proporcional à qualidade da ração que é oferecida ao mesmo, normalmente são oferecidas rações com elevados teores de energia e proteína, com nitrogênio em excesso para garantir que as necessidades nutricionais dos animais sejam atendidas (Gay \& Knowlton, 2009) e com isso a ração torna-se a principal fonte de nitrogênio produzido na avicultura (Mendes et al., 2012).
Porém a geração de grande volume de resíduos com relevante concentração de nitrogênio pode representar um inconveniente à qualidade do ar nas instalações de produção animal (OviedoRondón, 2008). Os dejetos depositados na cama aviária são responsáveis pela produção de gases no interior de uma instalação e constitui o principal meio de emissão de gases (Nääs et al., 2007; Oliveira \& Monteiro, 2013) uma vez que apenas $45 \%$ do nitrogênio consumido na ração é retido como proteína animal e o restante, cerca de $55 \%$, é excretado na forma de dejetos na cama (Silva et al., 2006), o fator de emissão de amônia nos dejetos é estimado em $35 \%$ do nitrogênio amoniacal excretado pelas aves (Misselbrook et al., 2010).

Com isso, são necessárias pesquisas que minimizem os impactos ao meio ambiente, visando qualidade do ambiente de produção e, assim, menor emissão de gases com potencial efeito estufa para o planeta, buscando sustentabilidade de produção, tanto em termos de segurança alimentar, garantindo um custo alimentar acessível a população em qualquer classe, como também a preservação do meio ambiente para gerações futuras (Marín, 2011).

\section{MEDIDAS PARA MINIMIZAR A EMISSÃO DE AMÔNIA}

Para reduzir os níveis de amônia nos ambientes de produção de frangos de corte pode-se fazer uso de diversas técnicas, uma vez que a emissão deste gás nas instalações é influenciada por diversos fatores, e entre eles destacam-se: o tipo de construção, a umidade da cama, as condições do macro clima local, como temperatura, ventilação e fluxo, velocidade e umidade relativa do ar (Miragliotta, 2005). Assim, o equilíbrio entre as condições ideais de ventilação e manejo do ambiente de alojamento é imprescindível para que se consiga sustentabilidade na produção de frangos de corte em regiões com condições de clima quente ou tropical como é o caso do Brasil (Nääs et al., 2007).

As concentrações máximas de amônia sugeridas por NIOSH - National Institute for Occupational Safety and Health (2001), indicam que os seres humanos podem estar expostos a $25 \mathrm{ppm}$, por 8 hs de permanência no ambiente, 35 ppm durante 15 min e 50 ppm por $5 \mathrm{~min}$. Para o caso dos animais, recomenda-se um nível máximo de 20 ppm de amônia para exposição contínua no interior das instalações, durante toda a fase de criação 
(Wathes et al., 1997; Owada et al., 2007). Na Tabela 1 são apresentados os efeitos e as características resultantes da presença de diferentes concentrações de amônia no ambiente.

Tabela 1. Efeitos e características de diferentes concentrações de amônia nos sistemas de produção animal

\begin{tabular}{|c|c|c|}
\hline $\begin{array}{l}\text { Amônia } \\
\text { (ppm) }\end{array}$ & Humanos & Animais \\
\hline 5 & $\begin{array}{l}\text { Detectável apenas por algumas pessoas } \\
\text { (Ritz et al., 2005) }\end{array}$ & \\
\hline 10 & $\begin{array}{l}\text { Facilmente detectável pelo cheiro (Ritz } \\
\text { et al., 2005) }\end{array}$ & \\
\hline 20 & $\begin{array}{l}\text { Limite de tolerância recomendado no } \\
\text { conteúdo do ar em ambientes } \\
\text { frequentados por trabalhadores com } \\
\text { jornadas de trabalho de até } 48 \text { horas } \\
\text { semanais. Nessa concentração o } \\
\text { ambiente é considerado medianamente } \\
\text { insalubre pela NR-15 (ABNT, 1978) }\end{array}$ & $\begin{array}{l}\text { As aves começam a sentir-se mal. } \\
\text { Concentração máxima recomendada para } \\
\text { o interior das instalações de produção } \\
\text { animal (Wathes et al., 1997; Owada et al., } \\
\text { 2007) }\end{array}$ \\
\hline 25 & $\begin{array}{l}\text { Máxima concentração permitida para } \\
\text { trabalhadores expostos por } 8 \text { horas de } \\
\text { permanência no ambiente (NIOSH, } \\
\text { 2001) }\end{array}$ & $\begin{array}{l}\text { Diminuição significativa do peso } \\
\text { corporal final dos frangos de corte } \\
\text { expostos durante toda a fase de criação, } \\
\text { chegando a ocorrer perdas de peso de } 90 \mathrm{~g} \\
\text { por aves ao final do lote (Lott \& Donald, } \\
2003 \text { ) }\end{array}$ \\
\hline 30 & $\begin{array}{l}\text { Tosse, dificuldade respiratória, } \\
\text { secreção de saliva, formação de } \\
\text { catarro, retenção de urina (Donham, } \\
\text { 2000) }\end{array}$ & \\
\hline 35 & $\begin{array}{l}\text { Máxima concentração permitida para } \\
\text { trabalhadores expostos por } 15 \text { minutos } \\
\text { de permanência no ambiente (NIOSH, } \\
\text { 2001) }\end{array}$ & \\
\hline 50 & $\begin{array}{l}\text { Irritação nos olhos. Máxima } \\
\text { concentração permitida para } \\
\text { trabalhadores expostos por } 5 \text { minutos } \\
\text { de permanência no ambiente (NIOSH, } \\
\text { 2001) }\end{array}$ & $\begin{array}{l}\text { Irritação nos olhos, queda na produção } \\
\text { pela incidência de doenças como: } \\
\text { aumento da secreção lacrimal, traqueíte } \\
\text { catarral, queratoconjuntivite e fotofobia } \\
\text { (Café \& Andrade, 2001) }\end{array}$ \\
\hline 100 & $\begin{array}{l}\text { Queimadura nos olhos, cegueira } \\
\text { temporária, irritação na pele (Perry, } \\
\text { 2003) }\end{array}$ & $\begin{array}{l}\text { Imediata redução da taxa de respiração } \\
\text { prejudicando os processos fisiológicos de } \\
\text { trocas gasosas quando chega a corrente } \\
\text { sanguínea, esse efeito tóxico pode levar a } \\
\text { óbito (Curtis, 1983) }\end{array}$ \\
\hline 500 & $\begin{array}{l}\text { Acesso de tosse violento, forte irritação } \\
\text { nos pulmões, edema pulmonar e até } \\
\text { mesmo morte (Perry, 2003) }\end{array}$ & $\begin{array}{l}\text { Dose letal mesmo durante curtos períodos } \\
\text { de exposição (Groot Koerkamp et al., } \\
1998 \text { ) }\end{array}$ \\
\hline
\end{tabular}




\section{Ventilação}

A ventilação como parte do acondicionamento térmico do ambiente em galpões avícolas permite alterar e controlar a qualidade do ar, provendo a renovação do ar, eliminando a amônia e outros gases do interior dos ambientes de produção (Tinôco, 2001). Normalmente no interior de uma instalação de produção de frangos de corte existem três camadas de ar distintas: a camada mais elevada próxima ao forro possui ar quente com elevados níveis de sulfeto de hidrogênio e amônia, uma camada intermediária onde predomina o ar mais puro e uma camada mais inferior com ar frio e dióxido de carbono proveniente da respiração das aves (Osório et al., 2009).

Existem equipamentos que atuam para minimizar os efeitos indesejáveis da amônia no ambiente, que é o caso da instalação de ventiladores ou exaustores, estes quando bem ajustados são imprescindíveis no controle da qualidade do ar e no conforto térmico dos animais. Tais equipamentos são responsáveis pela renovação do ar, amenizando os efeitos dos gases poluentes, entre eles, a amônia. Devem ser adequadamente instalados para que atendam as condições de bem estar dos animais, e com atenção à sua amplitude uma vez que o vento não pode ser direcionado ao chão para evitar levantamento de poeira da cama, prejudicando a respiração dos animais.

Os níveis de amônia no interior de uma instalação de produção de frangos de corte são mais elevados durante as primeiras semanas de vida das aves, quando a cama é reutilizada, e nesse momento ocorre a fase de aquecimento onde as instalações permanecem fechadas, durante a maior parte do tempo, adotando somente ventilação mínima para garantir a qualidade higiênica do ar e manter a temperatura adequada aos animais. À medida que os animais crescem a taxa de ventilação aumenta e com isso os níveis de amônia diminuem já que o aumento da ventilação promove redução da carga contaminante no interior da instalação (Miles et al., 2004).
Aumentar a taxa de ventilação é uma estratégia para diminuir os níveis de amônia dentro das instalações, pois além de diluir a sua concentração no ar favorece a remoção desse gás para o exterior da instalação. Esse aumento na taxa de ventilação promove também aumento da taxa de secagem da cama o que consequentemente diminui a volatilização da amônia (Gay \& Knowlton, 2009) uma vez que as reações dependem do teor de umidade, e quanto maior a umidade, maior degradação dos compostos nitrigenados e maior a conversão de amônio em amônia, que é a forma volátil.

A utilização de sistema de ventilação mínima ou higiênica, na fase inicial de criação, entre a primeira e a terceira semanas de vida das aves, mesmo durante o inverno, promove redução das concentrações de amônia a níveis inferiores aos limites considerados ideais pela literatura, ou seja, abaixo de $20 \mathrm{pm}$ (Wathes et al., 1997; Miragliotta, 2000; NIOSH, 2001; Jones et al., 2005; Owada et al., 2007) mantendo a qualidade do ar em condição adequada para as aves e trabalhadores (Vigoderis et al., 2010).

Entretanto o manejo da ventilação mínima ou higiênica pode não ser suficiente para possibilitar renovação do ar adequada e garantir a qualidade do ar, ou seja, livre da presença de amônia, no primeiro dia de alojamento de pintinhos de corte, sendo necessário adequar o manejo da ventilação mínima às condições relacionadas à cama aviária (Carvalho et al., 2011).

Por meio de um estudo de caso utilizando a técnica Delphi, que é um meio de agregar a opinião de uma série de especialistas, para melhorar a qualidade na tomada de decisão, os resultados mostraram que o uso da ventilação como forma de manter a cama aviária mais seca e diminuir a volatilização de amônia foi uma das medidas principais entre as melhores técnicas disponíveis para reduzir de forma geral as emissões de nitrogênio em instalações de produção de aves (Angus et al., 2003). Avaliando duas instalações similares, sendo que uma 
adotava sistema de ventilação positiva e a outra sem nenhum tipo de ventilação Vigoderis et al. (2010) observaram diminuição da temperatura do ar e redução de mais de $70 \%$ na concentração de amônia, na instalação sem ventilação a concentração média foi de 29 ppm e na instalação com ventilação foi de 23 ppm.

Associados ao sistema de ventilação podem ser adotados biofiltros e purificadores de ar. Nos sistemas de biofiltros ocorre um processo complexo de interações físicas, químicas e biológicas, o ar contaminado passa por uma coluna de biofilme onde ocorre difusão e biodegradação aeróbica para adsorção dos gases biodegradáveis e compostos voláteis, parte da amônia é retida por adsorção ao material da coluna, outra parte é absorvida por reações químicas e o restante é degradado por processo biológico de degradação, a amônia é oxidada a nitrito e o nitrito oxidado a nitrato (Baquerizo et al., 2005; Chen et al., 2005; Baquerizo et al., 2007; Baquerizo et al., 2009). Porém esses métodos só podem ser adaptados nas instalações com ventilação mecânica, a aplicação dessas técnicas pode reduzir de 80 a $90 \%$ as emissões (Brink et al., 2001).

\section{Características da cama}

A cama aviária é todo e qualquer material distribuído sobre o piso servindo de leito aos animais e pode ser constituída por uma série de materiais distintos, tem função de evitar o contato direto do animal com o piso, aumentar a área de superfície do chão, proteger as aves do frio do piso, favorecer a absorção de umidade e incorporar fezes, urina, penas, descamações de pele e restos de alimentos (Carvalho et al., 2011; Ritz et al., 2005). A produção de frangos de corte em cama sobreposta é o método de criação padronizado mais comumente utilizado no Brasil e no mundo (Angus et al., 2006).

As características da cama, como por exemplo, o número de reutilizações, é responsável pelo aumento da produção de gases poluentes dentro das instalações de produção animal, de maneira que, tanto as concentrações como o potencial de emissão estão vinculados as condições física, química e biológica da cama (Nääs et al., 2007). Dessa forma o manejo da cama é determinante na taxa de emissão de amônia nas instalações de produção de frangos de corte, uma vez que ajustando corretamente o conteúdo de umidade na cama é possível reduzir significativamente a produção de amônia (Abreu et al., 1998).

De acordo com o tipo de material de cama utilizado podem ocorrer variações no teor de amônia, foram observados menores teores de amônia em cama de pinus em relação a cama de grama, apesar de não haver diferença estatística na umidade dos dois tipos de cama estudados (Tomazelli et al., 2009). Entre os diversos tipos de cama estudadas por Carvalho et al. (2011) concluíram que os melhores resultados de qualidade em termos de $\mathrm{pH}$ e umidade, foram encontrados nas camas de casca de café e arroz além de que os teores de amônia observados no ambiente com esses dois tipo de cama estiveram dentro dos limites ideais recomendados para a produção de frangos de corte, ou seja, abaixo de 20 ppm.

Em função das características climáticas do Brasil e de países de clima subtropical, normalmente são utilizados aviários abertos o que possibilita condições de reutilização da cama por diversos lotes, podendo chegar a 14 lotes consecutivos (Oliveira \& Monteiro, 2013) essa reutilização pode causar aumento das emissões de amônia. Para não representar problemas, essa prática, que é muito utilizada em diferentes regiões do país, necessita de um tratamento para redução de riscos microbiológicos e dos teores de poluentes acumulados de um ciclo para outro (Ávila et al., 2008).

\section{Uso de aditivos na cama aviária}

O uso de aditivos sobre a cama aviária é uma das soluções mais práticas por ser uma medida rápida e econômica que pode reduzir a volatilização de amônia nos galpões avícolas por meio de alteração nas condições de $\mathrm{pH}$ e umidade da cama (Simioni Jr. et al., 2009; Bordignon, 2013; Oliveira; Monteiro, 2013), além de 
inibição da atividade da urease, limitando a hidrólise da uréia (Gay \& Knowlton, 2009; Ndegwa et al., 2008), sendo o controle da umidade da cama determinante no sucesso da aplicação de aditivos (Lott \& Donald, 2003).

$\mathrm{O} \mathrm{pH}$ determina o equilíbrio entre amônio $\left(\mathrm{NH}_{4}\right)$ e amônia $\left(\mathrm{NH}_{3}\right)(\mathrm{Ndegwa}$ et al., 2008). Com a alteração do pH, pela acidificação da cama, a emissão de amônia é reduzida, uma vez que o crescimento de microorganismos é prejudicado, dado ao meio de crescimento desfavorável, além de reduzir imediatamente a atividade das bactérias. Com pH abaixo de 7 a volatilização de amônia diminui pois os íons livres de $\mathrm{H}^{+}$aumentam a proporção entre amônio:amônia, ou seja, mais amônia é convertida a amônio que é uma forma

a)

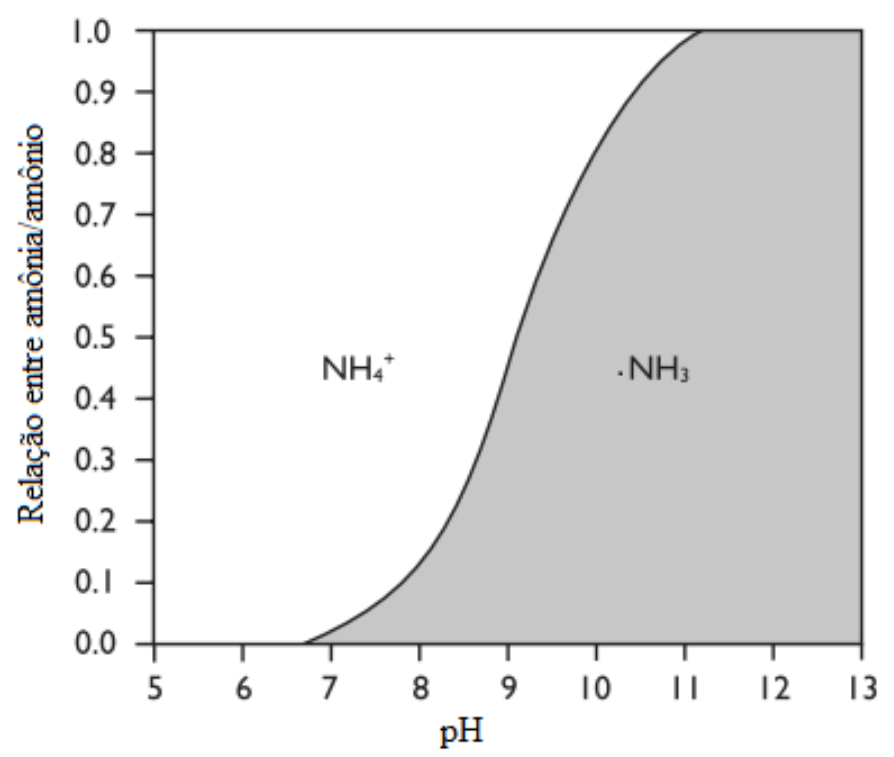

não volátil (França et al., 2014). Em pH em torno de 4,5 já não há evidência de nenhuma amônia livre mensurável (Ndegwa et al., 2008).

Existe efeito do $\mathrm{pH}$ sobre a quantidade e proporção de amônio e amônia formados, uma vez que na cama ácida a amônia é convertida a amônio, forma não volátil, assim como efeito do $\mathrm{pH}$ sobre a atividade microbiana na decomposição do ácido úrico em amônia que é extremamente importante para determinação da volatilização de amônia no ambiente (Gay \& Knowlton, 2009). Os dois processos de formação de amônia, relação amônio:amônia e degradação do ácido úrico, mencionados são potencializados em $\mathrm{pH}$ na faixa de 7 e 10 conforme Figura 1(a e b).

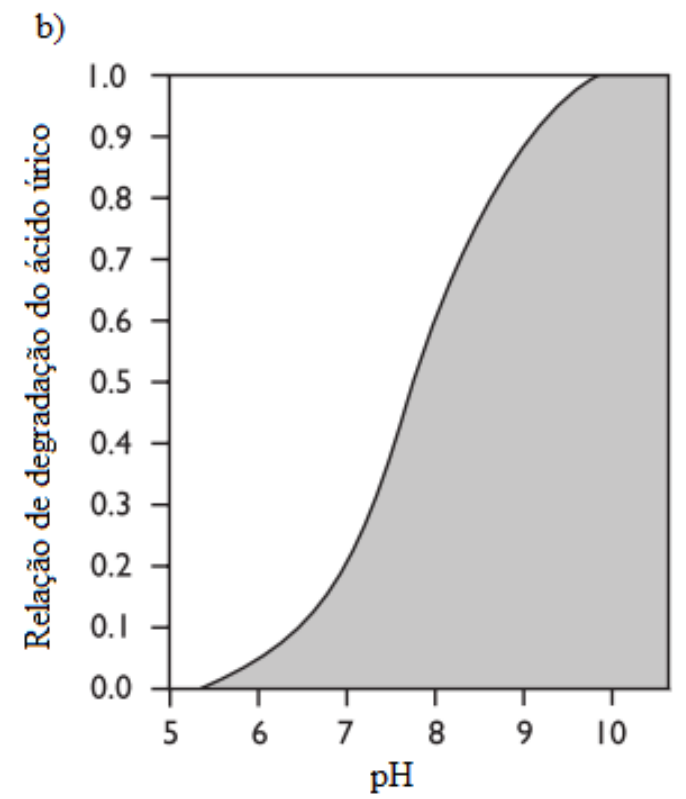

Figura 1. a) Relação amônio/amônia em função do pH. Adaptada de Gay; Knowlton (2009) e Ndegwa et al. (2008). b) Efeito do pH sobre a degradação do ácido úrico. Adaptada de Groot Koerkamp et al. (1998).

A enzima urease hidrolisa rapidamente tanto uréia quanto ácido úrico em amônio que rapidamente é convertido a amônia. A utilização de inibidores de enzimas, de uréases, aplicados na cama, bloqueia essa hidrólise e reduz a conversão da uréia e ácido úrico em amônio, o que torna essa técnica eficaz em diminuir a volatilização de amônia nos ambientes de produção animal (Bittman \& Mikkelsen, 2009; Ndegwa et al., 2008).

$\mathrm{O}$ sulfato de alumínio $\left(\mathrm{Al}_{2}\left(\mathrm{SO}_{4}\right)_{3}\right)$ é bastante efetivo para reduzir o $\mathrm{pH}$ da cama e, com isso, reduz exponencialmente a volatilização da amônia, principalmente nas quatro primeiras semanas do ciclo onde a renovação do ar é comprometida pela necessidade de aquecimento do ambiente (Oliveira et al., 2003). O sulfato 
de alumínio é capaz de reduzir significativamente o $\mathrm{pH}$ da cama pelo fato de que a dissociação de cada mol de sulfato de alumínio forma uma ácido com seis prótons livres (Moore Jr, et al., 2000) conforme Reação 1.

$$
\mathrm{Al}_{2}\left(\mathrm{SO}_{4}\right)_{3} .14 \mathrm{H}_{2} \mathrm{O}+6 \mathrm{H}_{2} \mathrm{O} \rightarrow 2 \mathrm{Al}(\mathrm{OH})_{3}+3 \mathrm{SO}_{4}^{2-}+6 \mathrm{H}^{+}+14 \mathrm{H}_{2} \mathrm{O}
$$

A aplicação de sulfato de alumínio mantém a concentração de amônia abaixo de 25 ppm nas primeiras semanas de criação dos animais, além de manter o ambiente saudável, livre de agentes patogênicos devido a sua elevada acidez, que proporciona redução significativa no pH da cama (Oliveira et al., 2004; Osório et al., 2009).

Outro aditivo utilizado normalmente para o tratamento da cama de frango, com finalidade de redução de emissão de amônia é o gesso agrícola $\left(\mathrm{CaSO}_{4}\right)$, que, por meio de reações químicas, aumenta a fixação do nitrogênio na forma de amônio $\left(\mathrm{NH}_{4}\right)$ evitando com isso o aumento da volatilização ou concentração de amônia no ambiente (Oliveira et al., 2003), a Reação 2 mostra a fixação da amônia pela adição de gesso agrícola.

$$
\mathrm{CaSO}_{4}+2 \mathrm{NH}_{3}+2 \mathrm{CO}_{2}+2 \mathrm{H}_{2} \mathrm{O} \rightarrow \mathrm{Ca}\left(\mathrm{HCO}_{3}\right)^{2}+\left(\mathrm{NH}_{4}\right) 2 \mathrm{SO}_{4}
$$

Menos utilizada a cal hidratada $\left(\mathrm{Ca}(\mathrm{OH})_{2}\right)$ melhora a qualidade da cama retendo o nitrogênio porém por um período mais curto, tendo efeito por cerca de duas semanas, sendo necessário nova aplicação após esse período (Oliveira et al., 2003).

Reduções significativas da amônia volatilizada foram observadas quando ácido muriático $(\mathrm{HCl})$ e ácido bórico $\left(\mathrm{H}_{3} \mathrm{BO}_{3}\right)$ são adicionados à cama aviária, sendo esses dois aditivos os que apresentaram resultados mais satisfatórios entre os diversos produtos químicos estudado (Silva et al., 2009).

\section{Redução do teor de proteína nas dietas}

Alterações no teor de proteínas e aminoácidos na dieta dos animais podem afetar a concentração de amônia e as emissões desta nas instalações (Gates et al., 2008), pois cerca de $55 \%$ do nitrogênio consumido na ração não é retido como proteína animal e sim excretado na cama (Silva et al., 2006). O monitoramento e a redução do teor de proteína bruta na dieta das aves com a suplementação de aminoácidos têm mostrado reduções nas perdas de amônia (Xin et al., 2004). O menor teor de nitrogênio possível de ser aplicado na ração irá reduzir a excreção de nitrogênio pelos animais (Jacob et al., 2000) e, consequentemente, as emissões de amônia no ambiente, sendo possível reduzir de 10 a $20 \%$ as emissões (Brink et al., 2001). Embora a excreção do nitrogênio fornecido nos alimentos não pode ser evitada, o controle cuidadoso dos teores de proteínas e aminoácidos na dieta pode ser utilizado para minimizar a quantidade de nitrogênio excretada nos dejetos (Gay \& Knowlton, 2009). A melhoria na composição dos alimentos é considerada como uma das principais medidas para reduzir as emissões de amônia nas instalações de produção de frangos de corte (Groot Koerkamp et al., 1998; Ndegwa et al., 2008).

A redução no teor de nitrogênio da dieta dos frangos de corte pode ser feita por meio de alterações na composição da matéria prima da ração e utilização de aminoácidos sintéticos. Porém essas alterações são restritas já que a produtividade dos animais não pode ser afetada (Brink et al., 2001) apesar das diferentes eficiências obtidas com a redução do teor de nitrogênio nas dietas não é possível reduzir totalmente a emissão de amônia por essa prática (Osorio-Saraz et al., 2014). 


\section{CONCLUSÕES}

A amônia produzida nos ambientes de produção de frangos de corte gera diversos danos aos animais, humanos e ao meio ambiente. A principal fonte de amônia nos dejetos depositados na cama é o nitrogênio excretado. A adoção de técnicas adequadas de manejo do

\section{AGRADECIMENTOS}

À Capes, Fapemig e CNPq.

\section{REFERÊNCIAS BIBLIOGRÁFICAS}

\section{ABNT - ASSOCIAÇÃO BRASILEIRA} DE NORMAS TÉCNICAS: NR15 Atividades e Operações Insalubres. Agentes químicos cuja insalubridade é caracterizada por limite de tolerância e inspeção no local de trabalho. Rio de Janeiro, 1978. 114p.

ABREU, P.G.; BAÊTA, F.C.; ABREU, V.M.N.; SOARES, P.R.; PERDOMO, C.C.; SILVA, M.A. Umidade da cama e teor de amônia em diferentes sistemas de aquecimento de frangos de corte. CONFERÊNCIA APINCO, 98 de Ciência e Tecnologia Avícolas. Anais...: 1998.Campinas: FACTA - Fundação Apinco de Ciência e Tecnologias Avícolas, 1998.

ANGUS, A. J.; HODGE, I.D.; MCNALLY, S.; SUTTON, M. A. The setting of standards for agricultural nitrogen emissions: A case study of the Delphi technique. Journal of Environmental Management, v. 69 (2003): 323-337, 2003. DOI: 10.1016/j.jenvman.2003.09.006

ANGUS, A.J.; HODGE, I.D.; SUTTON, M.A. Ammonia abatement strategies in livestock production: A case study of a poultry installation. Agricultural Systems, v. $89 \quad(1)$ : 204-222, 2006. DOI: $10.1016 /$ j.agsy.2005.09.003

ATIA, A. Ammonia Volatilization from Manure Application. Agri-Facts, v. 2008: 3-6, 2008.

ÁVILA, V.S.; OLIVEIRA, U.; ambiente, por meio de ventilação adequada e de manejo da cama, pelo controle de $\mathrm{pH}$, temperatura e umidade podem representar reduções significativas na emissão de amônia, bem como a utilização de aditivos e acompanhamento do teor de nitrogênio que é fornecido nas rações.

FIGUEIREDO, E.A.P.; COSTA, C.A.F.; ABREU, V.M. N.; ROSA, P.S. Avaliação de materiais alternativos em substituição à maravalha como cama de aviário. Revista Brasileira de Zootecnia, v. 37 (2): 273277, 2008.

BAQUERIZO, G., GAMISANS, X., GABRIEL, D., LAFUENTE, J. A dynamic model for ammonia abatement by gasphase biofiltration including $\mathrm{pH}$ and leachate modelling. Biosystems Engineering, v. 97 (4): 431-440, 2007. DOI:10.1016/j.biosystemseng.2007.03.031

BAQUERIZO, G., MAESTRE, J.P., MACHADO, V.C., GAMISANS, X., GABRIEL, D. Long-term ammonia removal in a coconut fiber-packed biofilter: Analysis of $\mathrm{N}$ fractionation and reactor performance under steady-state and transient conditions. Water Research, v. 43 (8): 2293-2301, 2009. DOI:10.1016/j.watres.2009.02.031

BAQUERIZO, G., MAESTRE, J.P., SAKUMA, T., DESHUSSES, M.A., GAMISANS, X., GABRIEL, D., LAFUENTE, J. A detailed model of a biofilter for ammonia removal: Model parameters analysis and model validation. Chemical Engineering Journal, v. 113 (2-3): 205-214, 2005. DOI:10.1016/j.cej.2005.03.003

BITTMAN, S.; MIKKELSEN, R. Ammonia Emissions from Agricultural Operations: Livestock. Better Crops, v. 93 (1): 28-31, 2009. 
BORDIGNON, L.A.F. Efeito de condicionadores químicos sobre a qualidade da cama de frango. Dissertação (Mestrado) - Universidade Tecnológica Federal do Paraná, 2013.

BRINK, C.; KROEZE, C.; KLIMONT, Z. Ammonia abatement and its impact on emissions of nitrous oxide and methane in Europe - Part 1: Method. Atmospheric Environment, v. 35 (36): 6299-6312, 2001. DOI: $10.1016 / S 1352-$ 2310(01)00434-4

CAFÉ, M.B.; ANDRADE, M.A. Intoxicações - Parte 2. In: Avicultura industrial. Ed 1091, 2001.

CARVALHO, T.M.R. DE; MOURA, D.J.; SOUZA, Z.M.; SOUZA, G.S.; BUENO, L.G. F. Qualidade da cama e do ar em diferentes condições de alojamento de frangos de corte. Pesquisa Agropecuária Brasileira, v. 46 (4): 351-361, 2011.

CHEN, Y.X., YIN, J., WANG, K.X. Longterm operation of biofilters for biological removal of ammonia. Chemosphere, v. 58 (8): $\quad 1023-1030, \quad 2005$. DOI:10.1016/j.chemosphere.2004.09.052

CURTIS, S. E. Environmental management in animal agriculture. Iowa. Iowa University Press. 1983. 410p. ISBN: 0-8138-0556-2

DONHAM, K. A historical overview of research on the hazards of dust in livestock buildings. In Dust Control in Animal Production Facilities, Proc. Congress in Aarhus. Anais...Horsens, Denmark: Danish Institute of Agricultural Sciences, Research Centre Bygholm. 2000.

FRANÇA， L.G.F.; TINÔCO, I. F.F.; MENDES, M.A. S.A.; COELHO, D.J. R. Caracterização de fatores que influenciam a emissão de amônia pelos dejetos de galinhas poedeiras e proposição de um score para o potencial máximo de emissão. XLIII Congresso Brasileiro de Engenharia Agrícola. Anais...Campo Grande: CONBEA 2014, 2014.

FURLAN, R. L. Influência da temperatura na produção de frangos de corte. In: VII
Simpósio Brasil Sul de Avicultura. Anais...Chapecó, SC - Brasil, p. 104-135, 2006.

GATES, R.S.; CASEY, K.D.; WHEELER, E.F.; XIN, H.; PESCATORE, A.J. U.S. broiler housing ammonia emissions inventory. Atmospheric Environment, v. 42 (14): 3342-3350, 2008. DOI: 10.1016/j.atmosenv.2007.06.057

GAY, S.W.; KNOWLTON, K.F. Ammonia emissions and animal agriculture. Virginia Cooperative Extension, v. 442 (110): 1-5, 2009.

GROOT KOERKAMP, P.W.G.; METZ, J.H.M.; UENK, G.H.; PHILLIPS, V.R.; HOLDEN, M..; SNEATH, R.W.; SHORT, J.L.; WHITE， R.P.P.; HARTUNG， J.; SEEDORF, J.; SCHRÖDER, M.; LINKERT, K.H.; PEDERSEN, S.; TAKAI, H.; JOHNSEN, J.O.; WATHES, C.M. Concentrations and Emissions of Ammonia in Livestock Buildings in Northern Europe. Journal of Agricultural Engineering Research, v. 70 (1): 79-95, 1998. DOI: 10.1006/jaer.1998.0275

JACOB, J.P.; IBRAHIM, S.; BLAIR, R.; NAMKUNG, H.; PAIK, I.K. Using Enzyme Supplemented, Reduced Protein Diets to Decrease Nitrogen and Phosphorus Excretion of White Leghorn Hens. Asian-Australasian Journal of Animal Sciences, v. 13 (12): 1743-1749, 2000. DOI: 10.5713 /ajas.2000.1743

JONES, E.K.M.; WATHES, C.M.; WEBSTER, A.J.F. Avoidance of atmospheric ammonia by domestic fowl and the effect of early experience. Applied Animal Behaviour Science, v.90 (3-4): 293-308, 2005.

LOTT, B.; DONALD, J. Amônia: Grandes perdas mesmo quando você não percebe. Avicultura Industrial. 2003. Disponível em:

<http://www.aviculturaindustrial.com.br/>. Acesso em: 23 mar. 2015.

MARÍN, O.L.Z. Caracterização e avaliação do potencial fertilizante $e$ poluente de distintas camas de frango submetidas a reusos sequenciais na zona 
da mata do estado de Minas Gerais. 2011. 68f. Dissertação (Mestrado) Universidade Federal de Viçosa, 2011.

MENDES, L.B.; TINÔCO, I.F.F.; SOUZA, C.F.; SARAZ, J.A.O. O ciclo do nitrogênio na criação de frangos de corte e suas perdas na forma de amônia volátil: uma revisão. Pubvet, v. 6 (20): 1-25, 2012.

MILES, D.M.; BRANTON, S. L.;LOTT, B.D. Atmospheric ammonia is detrimental to the performance of modern commercial broilers. Poultry science, v. 83 (10): 1650-1654, 2004. DOI: $10.1093 / \mathrm{ps} / 83.10 .1650$

MIRAGLIOTTA, M.Y. Avaliação dos níveis de amônia em dois sistemas de produção de frangos de corte com ventilação e densidade diferenciados. Dissertação (Mestrado) - Universidade Estadual de Campinas, 2000.

MIRAGlotTA, M.Y. Avaliação das condições do ambiente interno em dois galpões de produção comercial de frangos de corte, com ventilação e densidade populacional diferenciados. Tese (Doutorado) - Universidade Estadual de Campinas, 2005.

MISSELBROOK, T.H.; CHADWICK, D.R.; GILHESPY, S.L.; CLAMBERS, B.J.; SMITH, K. A.; WILLIAMS, J.; DRAGOSITS, U. Inventory of Ammonia Emissions from UK Agriculture. DEFRA Contract AC0112, v. 2010 (October): 134, 2010.

MOORE Jr., P.A.; DANIEL. T.C.; EDWARDS, D.R. Reducing phosphorus runoff and inhibiting ammonia loss from poultry manure with aluminum sulfate. Journal of Environmental Quality, v. 29 (1): 29-37, 2000.

NÄÄS, I.A.; MIRAGLIOTTA, M.Y.; BARACHO, M.S.; MOURA, D. J.; SALGADO, D.D. Qualidade da cama de frango em aviário convencional e em tipo túnel. Brazilian Journal of Biosystems Engineering, v. 1 (2): 103-115, 2007.

NDEGWA, P.M.; HRISTOV, A. N.; AROGO, J.; SHEFFIELD, R.E. A review of ammonia emission mitigation techniques for concentrated animal feeding operations. Biosystems Engineering, v. 100 (4): 453-469, 2008. DOI: 10.1016/j.biosystemseng.2008.05.010

NIOSH. National Institute for Occupational Safety and Health. Ministério do Meio Ambiente. Ontario Air Standards for Ammonia. v. 1988: 1-47. 2001.

OLIVEIRA, M.C.; ALMEIDA, C.V.; ANDRADE, D.O.; RODRIGUES, S.M.M. Teor de matéria seca, pH e amônia volatilizada da cama de frango tratada ou não com diferentes aditivos. Revista Brasileira de Zootecnia, v. 32 (4): 951954, 2003. DOI: 10.1590/S151635982003000400022

OLIVEIRA, P.A. V.; MONTEIRO, A.N.T.R. Emissão de amônia na produção de frangos de corte (FACTA, Ed.) CONFERÊNCIA FACTA. Anais...Campinas: CONFERÊNCIA FACTA, 2013.

OLIVEIRA, M.C.; FERREIRA, H.A.; CANCHERINI, L.C. Efeito de condicionadores químicos sobre a qualidade da cama de frango. Arquivo Brasileiro de Medicina Veterinária e Zootecnia, v. 56 (4): 536-541, 2004. DOI: 10.1590/S0102-09352004000400016

OSÓRIO, J.A.; TINÔCO, I.F.; CIRO, H.J. Ammonia : a review of concentration and emission models in livestock structures. Dyna, v. 76 (158): 89-99, 2009.

OSORIO-SARAZ, J.A.; FERREIRATINOCO, I. F.; GATES, R.S.; OLIVEIRA-ROCHA, K.S.; COMBATTCABALLERO, E.M.; CAMPOS-DESOUSA, F. Adaptation and validation of a methdology for determing ammonia flux generated by litter in naturally ventilated poultry houses. Dyna, v. 81 (187): 137143, 2014.2 DOI: 10.15446/dyna.v81n187.40806

OVIEDO-RONDÓN, E.O. Tecnologias para mitigar o impacto ambiental da produção de frangos de corte. Revista Brasileira de Zootecnia, v. 37 (Supl. 
Esp.): $\quad 239-252, \quad 2008 . \quad$ DOI: 10.1590/S1516-35982008001300028

OWADA, A. N.; NÃ̃̃S, I. A.; MOURA, I. J.; BARACHO, M. S. Estimativa de bemestar de frango de corte em função da concentração de amônia e grau de luminosidade no galpão de produção. Engenharia Agrícola, v. 27 (3): 611-618, 2007.

PERRY, G. C. Welfare of the Laying Hen. World's Poultry Science Association, Bristol, v. 27 - 431p, 2003.

RITZ, C.W.; FAIRCHILD, B.D.; LACY, M.P. Litter Quality and Broiler Performance. Cooperative Extension Service / The University of Georgia College of Agricultural and Environmental Sciences, Bulletin 1 (April): 1-1267, 2005.

SILVA, A.N.; ROCHA, F.T.; MATOSO, S.C.G.; MIGLIORANZA, F.J.; CRUZ, C.V.; BIANCHINI, E.; ROCHA, Y.H.; NETO, A. C. F.; FERREIRA, E. Uso de diferentes produtos químicos para controle da volatilização de amonia em cama de frangos. ZOOTEC 2009. Anais... Aguas de Lindóia - SP: Anais Associação Brasileira de Zootecnistas, 2009.

SILVA, Y.L.; RODRIGUES, P.B.; FREITAS, R.T.F.; BERTECHINI, A.G.; FIALHO, E.T.; FASSANI, É. J.; PEREIRA, C.R. Redução de proteína e fósforo em rações com fitase para frangos de corte no período de 1 a 21 dias de idade - Desempenho e teores de minerais na cama. Revista Brasileira de Zootecnia, v. 35 (3): $840-848, \quad 2006 . \quad$ DOI: 10.1590/S1516-35982006000300029

SIMIONI JR, J.R.; HOMMA， S.K.; GOMES, J.D.F.; PREDOSA, V.B.; XAVIER, J.K. \& CHAGAS, P.R.R. Efeito da aplicação de diferentes aditivos na cama. Emissão de Gases Associados à Produção Animal e ao Manejo de Dejetos. Anais... Florianópolis -SC: SIGERA - I Simpósio Internacional sobre Gerenciamento de Resíduos Animais, 2009.

TINÔCO, I. Avicultura Industrial: Novos
Conceitos de Materiais, Concepções e Técnicas Construtivas Disponíveis para Galpões Avícolas Brasileiros. Revista Brasileira de Ciência Avícola, v. 3 (1): 124, 2001.

TOMAZELLI, I.L.; ABREU, P.G.; ABREU, V.M.N.; FRANCISCON, L.; CESTONARO, T.; HASSEMER, M.J.; DALLA COSTA, C.A. Teor de amônia e condições ambientais de diferentes materiais de cama de frango. (FACTA Ed.) CONFERÊNCIA FACTA DE CIÊNCIA E TECNOLOGIA AVÍCOLAS. Anais... Porto Alegre: Anais dos trabalhos de pesquisa José Maria Lamas de Silva, 2009.

VIGODERIS, R.B.; CORDEIRO, M.B.; TINÔCO, I. F. F; MENEGALI, I.; SOUZA, J. P.; HOLANDA, M.C.R. Avaliação do uso de ventilação mínima em galpões avícolas e de sua influência no desempenho de aves de corte no período de inverno. Revista Brasileira de Zootecnia, v. 39 (6): 1381-1386, 2010.

WATHES, C. M.; HOLDEN, M. R.; SNEATH, R. W.; WHITE, R. P.; PHILLIPS, V. R. Concentrations and emissions rates of aerial ammonia, nitrousoxide, carbon-dioxide, dust and endotoxin in UK broiler and layer houses. British Poultry Science, v. 38 (1): 14-28, 1997.

XIN, H.; LIANG, Y.; GATES, R.S.; WHEELER, E.F. Ammonia Emission from Iowa Layer Houses. Midwest Poultry Federation Convention. Anais...St. Paul, MN: 2004. 